\title{
Drug Therapy Problem and its Contributing Factors among Pediatric patients with Infectious Diseases admitted to Jimma University Medical Center, South West Ethiopia: Prospective observational study
}

Desalegn Mechessa Feyissa ( $D$ Sinaawayya@gmail.com )

Mizan-Tepi University https://orcid.org/0000-0002-5781-0368

\section{Tsegaye Melaku}

Jimma University

Dula Dessalegn

Jimma University

Research article

Keywords: Drug therapy problem, Pediatric, infectious disease, Ethiopia

Posted Date: July 12th, 2019

DOI: https://doi.org/10.21203/rs.2.11292/v1

License: (1) (i) This work is licensed under a Creative Commons Attribution 4.0 International License.

Read Full License 


\section{Abstract}

Background: Drug therapy problem is a significant challenge to provide high quality health care service for the patients. It is associated with morbidity, mortality, increased hospital stay and reduced quality of life. Moreover, pediatric patients are quite susceptible to drug therapy problems. Thus this study aimed to assess drug therapy problem and its contributing factors among pediatric patients diagnosed with infectious disease admitted to pediatric ward of Jimma university medical center, from April ,2018 to June 30, 2018. Methodology: Prospective observational study was conducted among pediatric patients with infectious disease admitted to Jimma university medical center from April 01,2018 to June 30, 2018. Drug therapy problems were identified by using Cipolle's and strand's drug therapy problem classification method. Patient's written informed consent was obtained after explaining the purpose of the study. Patient's specific data were collected using structured questionnaire. Data was entered into Epi data version 4.0.2 and then exported to statistical software package version 21.0 for analysis. To identify predictors of drug therapy problems occurrence, multiple stepwise backward logistic regression analysis were done. The $95 \% \mathrm{Cl}$ was used to show the accuracy of data analysis and statistical significance was considered at p-value $<0.05$. Results: A total of 304 pediatric patients were included in the study. Of these, $226(74.3 \%)$ patients had at least one drug therapy problem during their hospital stay. A total of 356 drug therapy problems were identified among two hundred twenty six patients. Non-compliance $(28.65 \%)$ and dose too low $(27.53 \%)$ were the most common type of drug therapy problems while disease comorbidity [AOR=3.39, 95\% Cl= (1.89-6.08)], Polypharmacy [AOR=3.16, 95\% $\mathrm{Cl}=(1.61-6.20)]$ and more than six days stay in hospital [AOR=3.37, 95\% $\mathrm{Cl}=(1.71-6.64)$ were independent predictors of drug therapy problem occurrence. Conclusion and recommendation: Drug therapy problems were common in pediatric patients

with infectious disease in the study area. Presence of comorbidity, Polypharmacy and Prolonged hospital stay were the predictors of drug therapy problem in this finding. Therefore, to overcome the significant gaps in pediatric pharmaceutical care, clinical pharmacists, Pediatricians and other health care professional have to work in collaboration. Keywords: Drug therapy problem, Pediatric, infectious disease, Ethiopia

\section{Background}

Pediatrics are special population those younger than 18 years old. They differ from adults and within their age groups in body surface area, weight, and organ function development which affect the efficacy and safety of pharmacotherapy $(1,2)$. The immunity of the children is not well developed. This enable them vulnerable to serious and potentially lethal infectious disease (3).

Infectious disease is one of the most common medical problems of pediatric population in developing countries. As reported findings showed in sub-saharan African such as Egypt (4) and Ethiopia (5) about 70- $86.4 \%$ of infectious diseases were diagnosed among children. The most common infectious diseases identified among these children were sepsis, pneumonia, meningitis, malaria, acute gastroenteritis, upper respiratory tract infection and intestinal parasites. Therefore; antimicrobials such as penicillin $\mathrm{G}$ 
crystalline, gentamicin, ceftriaxone and ampicillin were routinely prescribed for managing these infectious diseases (6).

Antimicrobials are a cornerstone to treat infectious disease. However, its irrational selection and use will result the problem such as drug resistance, inappropriate dose, inappropriate frequency, inappropriate duration, adverse drug events and drug-drug interaction. Hence, health care professionals should give due attention during prescribing, dispensing and administering antibiotics for pediatric patients $(7,8)$.

Drug therapy Problem (DTP) is an event or circumstance involving drug therapy that actually or potentially interferes with desired health outcome. A potential DTP is not yet manifested, but if left unresolved, it may harm the patient. However, an actual DTP has results clinical manifestations like adverse drug reaction or therapy failure. DTPs may arise at all stages of the medication use process from prescription to follow up of the treatment $(9,10)$.

Different drug therapy problem classification systems are published in literatures. To date there is no consensus and uniform methods of classification of Drug therapy problem. However, according to Cipolle, Morley and Strand all DTPs can be categorized in to seven types including: Need additional drug therapy, unnecessary drug therapy, ineffective drug therapy, dosage too low, dosage too high, adverse drug reactions, and non-compliance $(11,12)$.

Different factors contribute for occurrence of DTPs. These includes: missing information, poor patient's knowledge of the drug use, poly-pharmacy, administration of drugs with a narrow therapeutic range, polymorbidity, hepatic and renal impairment (13). Pediatric group of populations are at high risk for drug therapy problems. This may be due to difference in drugs pharmacodynamics, pharmacokinetic and clinical heterogeneity such as weight, body surface area, age and organ function development which are the determinants of dose and drug selection. In addition to these, there are a limited number of studies available concerning safety and effectiveness of the drugs in this specific group of population (14).

The differences in drugs pharmacokinetics and pharmacodynamics observed in children influence the choice of the drug, dose, dosage form and dosing interval (15). The pediatric medication-use process is complex and error prone because of the multiple steps required in calculating, verifying, preparing, and administering doses (16). These factor make the pediatrics to be at high risk for drug-related problems. Therefore, all pediatric prescriptions and medication orders must be checked for its appropriateness of the dose, route and frequency with a pediatrics dosing reference (17).

Involvement of pharmacist in health care team have crucial role in preventing and resolving drug therapy problems. For instance, presence of pharmacist in the health care team and improved communication of patients with physicians, nurses and pharmacists were reduce the occurrence of medication errors in pediatric patients (18). Similarly, in 2013, Ermindo R et al (19) reported that pharmacists contributed in the therapeutic optimization and prevention of iatrogenic events in pediatric patients. Therefore, involvement of pharmacists in the care of patients with infections associated with improved clinical and economic outcomes (20). 
Infectious disease are the major causes of morbidity and mortality among children worldwide especially, in developing countries (21). Drug therapy is one of the main therapies in managing infectious disease. However; irrational use of drug therapy results serious clinical, economical and psychological problem.

Prevalence of drug therapy problems in pediatric patients varies from country to country. The prospective cohort study conducted in China revealed that 82 DRPs were experienced by 69 patients and overall prevalence of DRPs was $21.0 \%$ (22). A total of sixty two DTPs were identified among pediatric patients in Pakistan. The most frequent DTPs were untreated conditions (25.80\%), improper drug selection (19.35\%) and drug interactions (9.67\%) (23). Ineffective drug therapy, need additional drug therapy, drug interaction, adverse drug reaction and medication error were the common drug related problem reported in pediatric patients in different findings $(24,25)$.

Drug therapy problem is a key factor which will affect the outcome of therapy in pediatric patients. It is a clinical problem, unless intervention done on the spot of the problems occurrence and it must be identified and resolved in a manner similar to other clinical problems. Medication errors in pediatrics are common and $5 \%$ to $27 \%$ of all pediatric medication orders result in a medication error and pharmacists must contribute to their prevention (26). It causes significant mortality and morbidity. For example, In the United States it was reported that 7000 patient were died as a result of medication errors. Pediatric inpatients may have 3 times more medication errors than adult inpatients, and these errors are frequently harmful $(27,28)$.

Drug therapy problem caused pediatric patients to be admitted to the hospital. For example, a prospective observational study conducted among pediatric patients in Canadian teaching hospital showed that medication-related emergency department visit was found in $8.0 \%$ of patients. Out of these $65.0 \%$ were deemed preventable (29). Similarly study done in Brazilian hospital showed that $14.7 \%$ of the patients were admitted to pediatrics ward due to DRPs. Study done in Australia also reported that $4.3 \%$ of pediatric admissions were related to DRPs $(30,31)$.

Drug therapy problem also causes economic crisis in health care system. For example, in 1995 in USA, cost associated to drug-related morbidity and mortality was between $\$ 30.1$ billion and $\$ 136.8$ billion annually. Overall, in United States the cost of drug-related morbidity and mortality exceeded $\$ 177.4$ billion in 2000 . Hospital admissions accounted for nearly $70 \%$ ( $\$ 121.5$ billion) of total costs $(32,33)$.

Factors that contributes for occurrence of drug therapy problems in pediatric patients includes: polypharmacy, certain infectious and Parasitic diseases, type of admission, length of hospital stay and number of disease conditions (22,34-36).

The rate of potential adverse events due to medication was higher in pediatric. For instance, a study conducted in pediatric intensive care unit (PICU) showed the the presence of pharmacists in PICU reduced the rate of serious medication errors from 29 to 6 per 1,000 patient /days (37). Similarly, It had 
shown that in PICU, as a result of pharmacists interventions a total of $\$ 9,135$ cost per year was saved (38).

In general, prolonged hospitalizations, long-term care admissions, emergency department visits, additional physician office visits cost, morbidity, mortality and additional prescription drugs were some of the consequences associated with DRPs (39).

Pattern of infectious disease in pediatric wards varies from country to country. Infectious diseases are the most common medical diagnosis among pediatric patients in Ethiopia (40). The magnitude of drug therapy problems and its contributing factors was not assessed among these populations in study setting as well as in Ethiopia. Consequently, this research aimed at assessing drug therapy problem and its contributing factors in pediatric patients with infectious disease admitted to Jimma university medical center.

Significance of the study

Pediatric is one of the special populations that are at high risk for DTPs since they have quite different pharmacokinetics and pharmacodynamics from that of the adult. Worldwide there are a limited number of studies available which are related to drug therapy problem in pediatric patients, particularly with infectious disease.

In the study setting there was no prior finding that identify prevalence of drug therapy problem and its contributing factors among patient with infectious disease in pediatric ward. So that the investigator believes that the finding of this study will provide a great contribution for patients, health institutions and policy makers by assessing the magnitude of drug therapy problem, identifying the type and predictors of drug therapy problem and also carrying out on spot intervention for each drug therapy problem identified. It can also be used as an input in empowering pharmaceutical care service and forwarding the significance of clinical pharmacist in pediatrics ward in the hospital.

Finally the investigator forwarded recommendations for each concerns body that helps to minimize the occurrence of drug therapy problem in the future. The result of this finding had invaluable contribution in clinical, economical and humanistic outcome for patient, parents and health institution. It will also be used as an input for further researchers.

General objective

- To assess drug therapy problem and its contributing factors among patient with infectious disease admitted at pediatric ward in JUMC from April 1 to June 30, 2018

Specific objectives

- To assess the prevalence of drug therapy problem among patient with infectious disease admitted to pediatric ward in JUMC from April 1 to June 30, 2018 
- To identify type of drug therapy problem among patient with infectious disease admitted to pediatric ward in JUMC from April 1 to June 30, 2018

- To identify the causes of drug therapy problem among patient with infectious disease admitted to pediatric ward in JUMC from April 1 to June 30, 2018

- To identify contributing factors of drug therapy problem among patient with infectious disease admitted to pediatric ward in JUMC from April 1 to June 30, 2018

\section{Methods}

Study setting and period

This research was conducted from April to June 2018 at pediatric ward of Jimma university medical center (JUMC), which is located in Jimma town; $352 \mathrm{~km}$ Southwest of Addis Ababa, Ethiopia. JUMC is the only teaching and referral hospital in the south western part of the country with bed capacity of 600 . It provides services for approximately 9000 inpatient and 80,000 outpatient clients per year with a catchment population of about 15 million people. It has different wards. Pediatric ward is among the ward which has different unit such as: level I, Level II, neonatal unit, Intensive care unit and Oncology unit. Annually about one thousand six hundred twenty three patients with infectious disease admitted to pediatric ward of Jimma university medical center (41).

Study Design

A prospective observational study design was conducted over all pediatrics patients with infectious disease admitted to JUMC from April 01 to June 302018.

Source Population

All pediatric patients with infectious disease admitted to JUMC during study period.

Study Population

All pediatric patients with infectious disease admitted to JUMC during study period and who fulfill inclusion criteria.

Sample size and sampling technique

The sample size was calculated by using single population proportion formula based on the following assumption: $Z=(1.96) 2, P$ =the prevalence of DTP in Zewditu hospital (31.57\%) (35) with 95\% confidence interval $(\mathrm{Cl})$ and marginal error $(\mathrm{d})$ of $5 \%$

Due to technical limitations, Equation 1 has been placed in the Supplementary Files section. 
$n=332$

Whereas:

$\mathrm{n}$ - Sample size $=332$

$Z-$ Confidence interval at $95 \%=1.96$

P - The prevalence of DRP in pediatrics ward in Zewditu referral hospital in $2014=31.57 \%$.

$d-$ Margin of error $=5 \%$

The size of the population is less than 10,000 . Therefore; the sample size was corrected using the following correction formula.

Due to technical limitations, Equation 2 has been placed in the Supplementary Files section.

Where: $\mathrm{n}$ - Sample size $=332$

$N$ - Number of pediatric patients with infectious disease admitted to JUMC in 2017=1623 $\mathrm{NF}=$ adjusted sample size

So, the total sample size after $10 \%$ of non-response added $=303.6 \sim 304$ patients

All patients diagnosed with infectious disease admitted to pediatric ward during data collection period and who fulfilled the inclusion criteria were consecutively included in the study.

Inclusion and Exclusion criteria

Inclusion criteria

- Patients admitted to pediatric ward of JUMC with in the study period.

- Age less than 18 years old

- Patient diagnosed with at least one infectious disease during the study period

- Patients whose parents gave and signed the informed consent. 
- Readmitted patients for whom data was previously collected.

- Patient admitted in ICU

- The hospital admission was less than 24 hours

Study variables

Dependent variable

- Drug therapy problem

Independent variables

Disease and drug related variables Professional related \& other variables

- Number of drugs used . Type of admission

- Comorbidity - Duration of hospital stay

- Number of infectious disease - Culture

- Number of disease condition . Medication error

- Class of drug prescribed . Pharmacist intervention

\section{Patient related variables}

- Sex

- Age

- Weight

- Place of residence

Data collection process and data quality assurance

Data were collected through medical record reviews and patient interview using a prepared structured questionnaire which was translated to Afan Oromo and Amharic language for patient interview to collect information on adherence, socio-demographic, medication and disease related issues. The data collection format (Annex III) was prepared by reviewing different literatures for important variables that used to assess drug therapy problems and its contributing factors. Its content includes: patient details, diagnosis, comorbidities, duration of hospital stay, review of system and patient's investigations, intervention taken, current and past medications. The data collection involved four pharmacists (bachelor degree) and one supervisor to organize the whole activities daily. The principal investigator reviewed all filled format so that any suggestion and corrections was given soon. Data collectors reviewed the medical chart by using prepared standard questionnaires' for all patients who fulfills 
inclusion criteria daily for their drug related need. Recommendations was done by a panel of experts of clinical pharmacist and forwarded to physicians and/or other health care provider during rounds.

\section{DTPs Identification and Classification}

In this study drug therapy problems were classified according to Cipolle, Morley and Strand DTPs identification and classification method. The method was refined based on literature review and different treatment guidelines with further revision, and endorsement by panel of experts (Clinical Pharmacists).

The case (DTP) was identified by reviewing of patient's chart (pediatricians' note, Residents notes, medical interns' notes) and interviewing the parents/caregiver. The prescribed drugs were evaluated against different international (WHO 2016, CDC, Micromedex, Medscape, Nelson textbook of pediatrics $20^{\text {th }}$ edition, Naranjo scale and different therapeutic guidelines) and national guideline (Ethiopian pediatric hospital care 2016) for their appropriateness in the order of indication, effectiveness, safety and drug interaction. The identified DTPs were classified as unnecessary drug therapy, needs additional drug therapy, ineffective drug therapy, dosage too low, adverse drug reaction, dosage too high and noncompliance.

\section{Data Quality Assurance}

The Questionnaires were translated from English to Afan Oromo and Amharic, and back translated into English by independent person to assure its consistency. Data was compiled, cleared, coded and checked for completeness and accuracy before entering into Epidata manager version 4.0.2. Double entry verification was made and data was analyzed using statistical software package, SPSS version 21.0. Training was given for four data collectors. The data collectors were also strictly supervised daily and the principal investigator reviewed all filled format so that any suggestion and corrections was given soon. A panel of experts (clinical pharmacists) assessed whether the data collection format would measure what it was intended to measure, and if it was comprehensive enough to collect all the information needed to address the purpose and goals of the study. Then a pretest was done on $16(5 \%)$ patients and an appropriate change was made based on expert opinion.

\section{Data processing and statistical analysis}

All statistical tests were performed using statistical software package, SPSS version 21.0. Descriptive analysis was computed as frequency, mean and standard deviation (SD) for continuous variables and for categorical data. Binary logistic regression analysis was performed to examine the association between independent variables and drug therapy problem. In binary logistic regression analysis, variables with $p$ values $<0.25$ was selected for further multiple logistic regression analysis. Multiple logistic regression analyses were used to determine the independent predictors of occurrence of DTP. The Odds ratio with $95 \%$ confidence interval $(\mathrm{Cl})$ was calculated to measure the strength of association between predictor and outcome variables. Probability values less than 0.05 will be accepted as statistically significant. The out puts of processed data was presented using tables, graphs and figures accordingly. 


\section{Ethical consideration}

Ethical clearance was obtained from ethical review committee of jimma university,institute of health. This committee wrote aletter of permission dated the $30^{\text {th }}$ February 2018; with reference number "IHRPGD/205/18" to Jimma university medical center to seek it cooperation and access the data. Pateint's infprmed consent was obtained after explaining about the purpose and procedure of the study. When the child was too young to provide informed consent,it was obtained from parents/caregivers. All the responses were kept confidential.

\section{Operational definition and Definition of terms}

Infectious disease: is a disease caused by pathogenic microorganism such as bacteria, fungi, Virus, protozoa, worms and parasites.

Adverse drug reaction: is a noxious and unintended response to a drug which occurs at doses normally used for the prophylaxis, diagnosis, or treatment of disease that occurred during the study period (42).

Comorbidity disease: is a medical condition diagnosed other than infectious diseases and which its cause is not by microorganism .

Drug therapy problem: is any undesirable event experienced by a patient which involves, or is suspected to involve, drug therapy, and that interferes with achieving the desired goals of therapy, which can be identified using Nelson $20^{\text {th }}$,Ethiopian pocket of hospital care for pediatric 2016, WHO 2016, and different pediatrics books.

Medication error: any preventable event that may cause or lead to inappropriate medication use or patient harm while the medication is in the control of the health care professional, patient, or consumer (43).

Poly-pharmacy: defined as concomitant use of five or more prescription medications (44).

Pediatric Patient: is a patient whose age range from birth up to the age of 18 during the study period.

Neonate: pediatric age ranging from birth to 28 days

Infant: pediatric age ranging from 29 days to $\leq 1$ years

Toddler. pediatric age ranging $>1$ year to $\leq 3$ years

Preschool: pediatric age $>3 y e a r s$ to $\leq 5$ years

School age: pediatric age $>$ 5years to $\leq 10$ years

Adolescent: pediatric age $>10$ years to $\leq 15$ years 


\section{Results}

\section{Socio-Demographic characteristics of the study participants}

Among 304 study participants included for study analysis 171 (56.3\%) were male. About $116(38.2 \%)$ of study participants were infant with the mean age of $2.97 \pm 1.53$ years with the range of 3 days- 15 years. About $194(63.8 \%)$ of patients were residing in the rural area. The mean weight of patients was $11.06 \pm 9$ $\mathrm{kg}$ with the range of 1.12 to $38.9 \mathrm{~kg}$; nearly one third of them $92(30.3 \%)$ were weigh $<5 \mathrm{~kg}$ followed by weigh between 5-10 kg were 91(29.9\%) (Table 1).

\section{Clinical Characteristics of study participants}

Of 304 patients included in the study, more than half of the patients had comorbidity 204(67.1\%). About $42.1 \%$ of patients had stayed between six to ten days in hospital with the mean duration of $8.98 \pm 5.00$. Most of the patients $212(69.7 \%)$ were admitted to pediatric ward of JUMC by transferring from different health facilities. A total of 511 infectious diseases were diagnosed among all study participants. Nearly half of the study participants 145 (47.7\%) had single infectious disease (Table 2). The most common infectious diseases diagnosed during the study period were meningitis $86(28.3 \%)$ followed by pneumonia76 (25\%) and late onset neonatal sepsis 63(20.7\%) (Figure 1) A total of 305 different comorbidities were diagnosed among 204 patients. The most common comorbidities were severe acute malnutrition (21.96\%) followed by anemia (21.63\%) and first episode of asthma (8.19\%) (Figure 2).

\section{Medication related information of study participants}

A total of 1305 drugs were prescribed for 304 patients during study period. The mean number of drug per patients was $4.29 \pm 1.74$. The most commonly prescribed drugs were Paracetamol $192(63.1 \%)$ followed by Ceftriaxone 186 (61.2\%) and Gentamycin 161 (53\%) (Figure 3). Among study participants; $127(41.77 \%)$ of them had polypharmacy (Figure 4).

\section{The Types and prevalence of Drug therapy Problems}

From a total of 304 patients, 226 patients experienced drug related problems, with overall prevalence of $74.3 \%$. During the study period a total of 356 DTPs were identified. From the study participants, 129 (57.1\%) males' patients were exposed to drug therapy problems. The most common DTPs identified were non-compliance 102 (28.65\%) followed by dose too low 98(27.53\%) and in effective drug therapy 41 (11.5\%) (Figure 5).

From 226 patients who had experienced DTPs, half of the patients $126(55.75 \%)$ had one drug related problems, while 77 (34.07\%) patients had two DTPs (Figure 6).

\section{Drugs involved in Drug therapy Problems}


Different classes of drugs were involved among the patients with drug therapy problems. The most class of drugs involved in DTPs were systemic anti-infective 271(76.12\%) followed by Central nervous system medicine 16(4.49\%). The most common drugs involved in DTPs were Gentamicin 62(22.87\%) followed by Ampicillin 49(18.08\%) (Table 4).

\section{The Types and status of interventions carried out}

The most common type of pharmacists interventions provided were change of the medication 89 (25\%) followed by adherence andcounseling79(22.19\%)(Figure7). From the proposed interventions about $69.38 \%$ were fully accepted. In general the acceptance rate was $79.49 \%$ ( Table 5).

\section{Factors associated with drug related Problems}

The result of bivariate analysis of independent variables and drug related problem showed that presence of comorbidity [COR=3.92, 95\% Cl:(2.29-6.74) P=0.0001], polypharmacy [COR=4.57, 95\% Cl:(2.42-8.62) $\mathrm{P}=0.00001]$, presence of more than three infectious disease [COR=2.95, 95\% Cl: $(1.16-7.49) \mathrm{P}=0.022$ ], type of admission [COR=1.78, 95\% Cl: (1.03-3.06) P=0.036] ,duration of hospital stay 6-10 days [COR=3.70, 95\% Cl:(1.98-6.94)P=.0004] and more than ten days stay in hospital [ $\mathrm{COR}=4.39,95 \% \mathrm{Cl}$ : (2.20-8.75) $\mathrm{P}=.0002$ ], presence of two medical conditions [COR=2.68, 95\% Cl:1.30-5.51], three medical conditions [COR=4.35,Cl:(2.01-9.40)] and more than four medical conditions [COR=6.67,Cl: (2.79-15.92)] were significantly associated with DTPs (Table 6).

\section{Predictors of DTPs occurrence in study populations}

Multivariate logistic regression analysis was carried out to identify independent predictors of occurrence of DTPs among the study participants. Accordingly, comorbidity, Polypharmacy and prolonged hospital stay were found to be independent predictors of drug related problems among study participants. It was found that the likely hood of having DTPs increases as duration of hospital stay increases. Patients with the duration of hospital stay 6-10 days were about three times more likely to have DTPs [AOR=3.37, 95\% $\mathrm{Cl}=(1.71-6.64)]$ whereas those stayed more than ten days in hospital were about four times more likely to have DTPs [AOR=3.86, 95\% Cl:1.84-8.08] as compared to those stayed $\leq 5$ days. It was found that patients who had polypharmacy were about three times more likely to have DTPs [AOR=3.16, 95\% (Cl: 1.61-6.20)] compared to those who had no polypharmacy. Similarly, patients with comorbidity were three times more likely to experience DTPs [AOR=3.39, 95\% Cl: (1.89-6.08)] than patients without comorbidity. Therefore, presence of comorbidity, polypharmacy and prolonged hospital stay were the predictors of drug therapy problems among pediatric patients with infectious disease in this study [Table 7].

\section{Discussion}

Study of potential drug therapy problem in pediatric patients is very essential in the prevention of complications arising from drug therapy problem (50). The prevalence and nature of all type of drug therapy problems among pediatric patients with infectious disease in pediatrics ward of JUMC had not 
been studied previously. Of the children included in the study, 226(74.3\%) of the them had experienced at least one drug therapy problem during their hospital stayed. This showed that DTPs were common among pediatric patients with infectious disease in the study setting.

Prevalence of DTPs among pediatric patients varies from study setting to setting. In this finding the prevalence of DTPs was found to be $74.3 \%$, which was higher than that of the study conducted in Hong Kong (21\%), Ethiopia (31.57\%) and United Kingdom and the Kingdom of Saudi Arabia (45.2\%) $(22,34$, 35). This difference might be due to the difference in hospital setting, difference in drug therapy problems classification used and the availability of trained prescribers and clinical pharmacists in pediatric ward.

According to our study, being male had higher percentage of DTPs than female with the odd of $11.4 \%$. However, the difference was statistically insignificant. Other findings also reported that DTPs were more frequent in males than in female. But, it was statistically insignificant $(22,35,45)$. This indicated that drug therapy problems could be occurred irrespective of the sex.

The type and cause of drug therapy problems were reported in this finding. The most common drug therapy problem identified was non-compliance (28.65\%) which was comparable with study done in Cote divoire $(24.1 \%)(46)$. The reason may be due to majority of the patients were prescribed with multiple drugs that contributed for not to afford \& difficulty in understand the instructions of drugs. Moreover, the caregiver might had less knowledge of drug use.

In the present study (27.52\%) of the DTPs was found to be dose too low. This was in line with a study done in London (21.7\%), Canada (19\%) and Egypt $(21.09 \%)(25,29,45)$. Dose too high was found to be (10.95\%) in the present study which was lower than the study done in Hong Kong 19.3\% (22).

This showed that inappropriate doses are more common in pediatrics which might be because of weightbased dose calculation, fractional dosing and incorrect recording of patients' weights and prescribing error (51).

ADRs are one of the major causes of iatrogenic disease, and they are as old as medicine itself. Pediatric patients may experience specific adverse effects not suffered by adults; thus pediatric patients are susceptible population to adverse drug reactions (52). Overall, incidence of patients experiencing ADR in this study was found to be $2.81 \%$ which was in line with the finding reported by Rashed et al (22) and study done in Toronto( $2.5 \%$ ) (48). The most common adverse drug reaction experienced by patients was maculopapular rash due to antibiotics such as clotrimazole and ceftriaxone. The rare adverse event such as Redman's syndrome was also reported in this finding after concomitant use of Vancomycine and ciprofloxacin. This showed that drug-drug interaction is a major factor that might cause ADR which harm patients (53).

In this study need additional drug therapy was (11.24\%) which was in agreement with study done in British (9.9\%) (45). In our study unnecessary drug therapy was $7.3 \%$ which was in line with study done in Addis Ababa (35). However, this finding was two times higher than study done in United Kingdom and 
Saudi Arabia (3.8\%) (34).This indicated that duplicate drug therapy was common in study area that contributes for the patient to pay extra cost and expose them for potential ADR and drug interaction. Therefore, Prevention of duplicate drug therapy will contribute in cost saving among hospitalized patients.

The class of drugs most frequently involved in drug therapy problems was anti-infective $76.12 \%$; which was similar with the finding reported by Rashed et al (22), Deepishka P et al (49) and Ermindo R et al(19) where systemic anti-infective were the most frequent drugs involved in DRPs. In this finding, the drugs frequently involved in DTPs were gentamicin and ampicillin. It was in contrast to study done in United Kingdom and Saudi Arabia the whereas Amoxacillin and cimetidine were the most frequent drug involved in DTPs (34). The difference might be due to these drugs were the first line drugs for infectious disease such as meningitis, pneumonia and sepsis that were prevalent in the study setting. Furthermore, these drugs were frequently prescribed than others drugs in the study setting.

The result of bivariate logistic regression analysis of independent variables and drug therapy problem showed that comorbidity, polypharmacy, number of infectious disease, type of admission, number of disease condition and length of hospital stay were associated with drug therapy problem. However, in multivariate analysis, comorbidity, length of hospital stay and polypharmacy were found to be independent predictors of drug therapy problem among pediatric patients diagnosed with infectious disease admitted to JUMC. Similarly, study done in Zewditu hospital (35), Hong Kong (22) and United Kingdom and Saudi Arabia(34) indicated that polypharmacy was the predictors of DTPs in pediatrics. This might be due to the fact that the more the number of drugs prescribed, the more drug-drug interaction, more ADR and the more medication error. Moreover, it could also increase the medication cost on patients which contribute to non-adherence that inturn increase DTP.

In this finding prolonged hospital stay was the predictor of DTPs. Similarly, the finding reported by Eshetie et al (36) and Dedefo et al (47) supported that prolonged hospital stay was the risk factor for the occurrence of DTP. The possible reason could be the more the patient stayed in hospital, the more likely the patient had chance to acquire new infection such as hospital acquired infection and health care associated infection. These infectious disease need new and more complex medications which further contribute for occurrence of drug therapy problem. Beside to this, most of the study participants had prolonged hospital stay,comorbidity and they had been prescribed with the average of four drugs per patients which increased likely hood of experiencing DTPs in the study patients

In the current study, presence of comorbidity was one of independent predictors for DTP. This was also supported by the finding reported by Zed et al (29). The reason might be presence of comorbidity influence the desired outcome of other disease by increasing number of drugs, causing disease-disease interaction, drug-drug interaction, drug-disease interaction which collectively result in increased likely hood of experiencing DTPs in the study patients.

Clinical pharmacist involvement in inpatient pediatric care can significantly help to identify, resolve and prevent the drug therapy problems (48). In this finding the most common type of interventions provided 
was change of the medication (25\%) which was similar with study done in India (50). However, it was higher than that of study done in Tirupathi (6\%) (49).

This discrepancy might be due to ineffective drug therapy, which need changing of the medication, was not assessed in the finding reported from Tirupathi. Adherence and counseling (22.19\%) provided for patients was higher than finding reported by Rashed et al (22). The discrepancy might be due to dosing problem was the most common type of DTP whereas non-compliance was most common DTP in this finding.

In the present study majority of intervention provided were accepted (79.49\%); which was in line with study done in Toronto(81\%) (48). This showed that DTPs can be prevented through effective communications and collaboration among clinical pharmacists, physicians, nurses and as well as patients (54)

\section{LIMITATION OF THE STUDY}

- Since the study was conducted in single center, it may lack external validity.

- The study did not classify DTPs in its severity level that means mild, moderate and severe due to the complexity of the study

\section{CONCLUSIONS}

The present finding showed that the prevalence of drug-related problems were high at pediatric ward of Jimma University medical center that needs great attention. The most frequently identified DTPs were non-compliance, followed by dose too low and ineffective drug therapy. The finding revealed that presence of comorbidity, poly-pharmacy and prolonged hospital stays were independent predictors of DTPs. From overall interventions provided, change of medications, adherence and counseling and change in drug dose were the common. The acceptance rate of recommendation by clinical pharmacist was high.

\section{RECOMMENDATIONS}

The prevalence of drug therapy problems were found to be high. Therefore, the following recommendations are forwarded based on the result of the study.

\section{For Jimma university medical center}

- Clinical pharmacists have be recruited and assigned to pediatric ward of Jimma university medical center in order to provide better pharmaceutical care services.

- The hospital have to establish the forum that encourage physicians, nurses and pharmacist relationship for better pharmaceutical services

- Medication education program for caregiver/family have to be established in the hospital 


\section{For health professionals who work in Pediatric ward of JUMC}

- Pediatrians

- Consult clinical pharmacists for complicated cases with complex medications regimen for better outcome

- Follow the recommended guidelines while prescribing the drug frequency and drug dose.

- Nurses

- Check and calculate the correct drug dose while administer the drug for the patients

- Consult pharmacist for any confusion about drug before administering the drug for the patients

\section{For Department of clinical pharmacy}

Pediatrics are special population whom their medical management required special attention. Therefore, health care professionals who have deep knowledge of pediatric pharmacotherapy are needed.

So that department of clinical pharmacy should:

- Establish physicians and clinical pharmacists scientific presentation session on pediatrics pharmacotherapy regularly

- Provide training on antibiotics related problem, medication administration technique for health professional working in pediatrics ward of JUMC.

- Establish antibiotic stepwardship program

\section{For patients/caregiver}

- Take/give his/her medicine as prescribed if you have forgeton the instructions how to provide the drugs, ask pharmacist or health professional before providing for the patients

\section{For federal ministry of health /policy maker}

- Have to strengthen the reporting and monitoring mechanism of drug therapy problem

\section{For researchers}

- Conduct a research on clinical, economical and humanistic impact of drug therapy problem among pediatric patients with infectious disease admitted to the study area.

\section{References}

1. 1. Brian K, Robin L, Michael E, Joseph B, Pamala A,Wayne A et al. Pediatrics. In: Marcia L. Aplied therapeutics and the clinical use of drugs. 10th edition.New York, Lippincott William \& Wilkins ,2013. p. 2265. 
2. Vinita B, Phan H and Milap C. Pediatrics. In: Marry A, Terry L,Barbara G,Jill M,Joseph B \& Patrick. pharmacotherapy practice and principle. 4th ed: McGraw-Hill Education; 2016.p. 1663

3. Sheppard J. Strengthening your child's immune system. pathways to family wellness. 2017(4):1. http//:www. pathwaystofamilywellness.org accessed date september 10th , 2018 at 2:00 PM at Jimma university

4. Shaimaa M, Mohemed Y, Nahla F and Dina N. Frequency and characteristics of common infectious disease among children under 5 years old presenting at Giza. Egyptian Journal of Community Medicine. April ,2017;35(2):49-55.

5. Agalu A and Mekonnen H. Drug prescribing practice in a pediatric ward in Ethiopian. International Research Journal of Pharmacy and Pharmacology. 2012;2(6):132-8. .

6. Kahsay $\mathrm{H}$, Abrham H, Eyob $\mathrm{T}$ and Kumela K. Antimicrobial use in paediatric patients in a teaching hospital in Ethiopia. Journal pone PLOS ONE. March 6, 2017;12(3):1-8.

7. Lishan A, Getu B and Zelalem A. Antibiotics Use Evaluation for Pediatrics at Nekemte Referral Hospital, East Wollega Zone, Oromia Region, West Ethiopia. World Journal of Medical Sciences. 2016;13(1):17-26.

8. Nicolini G. Combating the rise of antibiotic resistance in children. Minerva Pediatr. 2014;66(1):31-9.

9. Zuidlaren. Classification scheme for Drug-Related Problems. PCNE classification May 2006;5(1):1-4.

10. Viktil K and Blix H. The Impact of Clinical Pharmacists on Drug related Problems and Clinical Outcomes. Basic Clin Pharmacol Toxicol. 2008;102((3)):275-80.

11. Robert J, Linda M and Peter C. Drug therapy problems. In: Robert J, Linda M, Peter C, editor. Pharmaceutical Care Practice the clinician's guide. 2nd edition. New York,Mc Graw-Hill's Acess Pharmacy, 2004.

12. Reddenna L and Nagavalli S. Drug Therapy Problems. PharmaTutor. 2014;2(2):111-6.

13. Kaufmann C, Stampfli D, Kurt E and Markus L. Determination of risk factors for drug related problems. British medical Journal. 2015;5(6):1-8.

14. Garner S , Hill E, Irving M, Bissinger R and Annibale D. Prospective controlled study of an intervention to reduce errors in neonatal antibiotic orders. Journal of perinatology. 2015;35(8):631-5.

15. Wood A, Abdel M., Alander S, Blowey D and Leeder J. Developmental pharmacology-drug disposition, action, and therapy in infants and Children. N Engl J Med. 2003;349:1157-67.

16. Richard K, Marjorie A, Glenn D, Sidney C, Linda E and Jan F. Pediatrics. Merck manual of diagnosis and therapy. 19th edition. USA: Gary Zelko; 2013.

17. Milap C and Taketomo C.Pediatrics. In: Joseph T, Robert L, Gary C, Gary R, Barbara G and Michael. Pharmacotherapy A pathophysiologic approach. $9^{\text {th }}$ edition. New York. McGraw-Hill Education, 2014.

18. Fortescue E, Landrigan C, McKenna K, Clapp M, Federico F, et al. Prioritizing strategies for preventing medication errors and adverse drug events in pediatric inpatients. . Pediatrics. 2003;111(4):722-9.

19. Prot-Labarthe S, Paolo D, Lavoie A, Quennery S, Francois J, Bourdon L et al. Pediatric drug-related problems : a multicenter study in four French-speaking countries. Int J Clin Pharm. 2013;35(2):251-9. 
20. Robert M, Steven J, Martin and David F. Clinical and economic outcomes of involving pharmacists in the direct care of critically ill patients with infections. Critical Care Medicine 2008;36(12):3184-9

21. Collaboration G. Global and national burden of diseases and injuries among children and adolescents: findings from the Global Burden of Disease 2013 Study. JAMA Pediatrics. 2016 170(3):267-87.

22. Asia N, Charles C, Y Benjamin , Leung S and lan C. Epidemiology and potential risk factors of drugrelated problems in Hong Kong paediatric ward. Br J Clin Pharmacol 2015;77(5):873-9.

23. Alia G, Nazir S, Khana A, Abbas M, Samiullah et al. Assessment of Effective Clinical Pharmacy Clerkship as an Emerging Programme on Drug Related Problems in Pediatric Ward- A Single Centre Study from North West Part of Pakistan. Newsletter. 2013;1:11- 29.

24. Omed D, Ahmed T and Abdulrahman S. Drug related problems in sulaimani pediatric teaching hospital, Iraq. World Journal of Pharmaceutical Sciences. 2014;2(6):534-8.

25. Ahmed N, Farid S and Dawoud D. Drug-related problems in cardiac children in Egypt. Minerva Pediatr April, 2016;68(2):89-95.

26. Ghaleb M, Yeung V, Khaki Z and Wong I. Systematic review of medication errors in pediatric patients. Ann Pharmacother. 2006;40(10):76.

27. Federico $F$ and Robert $A$. Medication errors and adverse drug events in pediatric inpatients. JAMA. 2001;285(16):2114-20.

28. Rinke M, Bundy G, Velasquez A, Sandesh R, Yasmin Z, Marlene R et al. Interventions to Reduce Pediatric Medication Errors:A Systematic Review. Pediatrics 2013;134(2):338-60.

29. Peter J , Eleanor A, Nancy G, Neil J, Doug S,Janet A et al. Medication-Related Emergency Department Visits in Pediatrics: Prospective Observational Study.Pediatrics.2015;135(3):433-43.

30. Kylie L, Chapman B and Brien E. Frequency and characteristics of hospital admissions associated with drug-related problems in paediatrics. Br J Clin Pharmacol. 2004;57(5):611-15.

31. Moriel P, Visacri D, Ambrosio R, Serian A and Santi I . Drug-related problems cause admissions to Brazilian hospital paediatric emergency unit. Eur J Hosp Pharm.2002;19(97):1-9.

32. Johnson J and Amy J. Drug-related morbidity and mortality.A cost-of illness model. Arch Intern Med. 1995;155:1949-56.

33. Johnson J and Amy J. Drug-Related Morbidity and Mortality: Updating the Cost-of-Illness Model. Am Pharm Assoc. 2001;41:192-9.

34. Asia N, Neubert A, Stephen T, John J, Hani A, Adnan A et al. Epidemiology and potential associated risk factors of drug-related problems in hospitalized children in the United Kingdom and Saudi Arabia. European Journal of Clinical Pharmacology.December, 2012; 68(12):1657-66.

35. Kassa M , Balcha T and Shibeshi W. Assessment of drug-related problems in pediatric ward of Zewditu Memorial Referral Hospital,Addis Ababa, Ethiopia. International Journal of Clinical Pharmacy. October, 2017;39(5):1039-46. 
36. Tesfahun C, Bisrat H, Negussu M, Getahun P, Alemayehu B and Tsinuel G. Adverse drug events in hospitalized children at Ethiopian University Hospital. BMC Pediatrics. 2015;15(83).

37. Wang J, Kaushal R, Park C, Mochizuki C and Weingarten S. Prevention of pediatric medication errors by hospital pharmacists and the potential benefit of computerized physician order entry. Pediatrics 2007;119(1):77-85.

38. Kaushal R, Abramson E, Soukup R and Goldmann A. Unit-based clinical pharmacists $\$ prevention of serious medication errors in pediatric inpatients. Am J Health Syst Pharm. 2008;65(13):1254-60.

39. Chapman B, Kylie $L$ and Brien E. Frequency and characteristics of hospital admissions associated with drug-related problems in paediatrics. Br J Clin Pharmacol. 2004;58(5):611-15.

40. Dagnew M, Dawit S and Daniel B. Analysis of admissions to the pediatric emergency ward of Tikur Anbessa Hospital in Addis Ababa, Ethiopia. Ethiopian Journal of Health Development September 2007;21(1).

41. Health management information system: Jimma University, september, 2018.

42. World health organization. Adverse reaction 1972. p. 5.

43. World health organization. Medication Errors. 2016. p. 5.

44. Bjerrum L, Sogaard J and Halla S. Polypharmacy in general practice:differences between practitioneres. Br J Gen Pract 1999;49(440):195-8.

45. Ibrahim N, Wong I ,Tomlin S, D Manish, Rees L and Jani Y. Epidemiology of medication-related problems in children with kidney disease in london. Pediatr Nephrol 2015;30:623-33.

46. Pascal D PC, Marius Bi, Doffou E and Amorissani M. Assessment of a Clinical Pharmacy Activity in a Pediatric in Cote d囚ivoire. Journal of Basic and Clinical Pharmacy Dec-Feb, 2017;8(1):15-9.

47. Gebre M, Haileamlak A and Tarekegn.M. Incidence and determinants of medication errors and adverse drug events among hospitalized children in West Ethiopia. BMC Pediatrics. 2016;16(81):110.

48. Tracey L, Darcy Nicksy and Cindy Girvan. Clinical pharmacy services in a pediatric hematology/oncology clinic. Can J Hosp Pharm. 1999;52:18-23.

49. Deepishka P, Sai D, Maanasa A and Durga P. Assessment of drug related problems and clinical pharmacist interventions in paediatric department of a tertiary care teaching hospital. International Journal of Basic \& Clinical Pharmacology October 2018;7(10):1934-9.

50. Jose B, Shareef $J$ and Shenoy R. Assessment of Drug Related Problems and Pharmacist Interventions in Pediatric Drug Therapy in a Tertiary Care Teaching Hospital in India. Am J PharmTech Res. 2016;6(2):210-18.

51. Lesar $T$, Briceland $L$ and Stein $D$. Factors related to errors in medication prescribing. JAMA Pediatrics. 1997;277(4):312-7.

52. Kishour K, Aakash P, Saini G, and Rajni B. Pattern of Adverse Drug Reactions in Children Attending the Department of Pediatrics in a Tertiary Care Center: A Prospective Observational Study. Clin Med Insights Pediatr 2015;11(9):73-8. 
53. Moura C, Acurcio F and Belo N. Drug-Drug Interactions Associated with Length of Stay and Cost of Hospitalization. J Pharm Pharm Sci 2009;12 (3):266 -72.

54. Vimali. M, Reddy S and Ranganayakulu. D. Analysis and categorization of Drug Related Problems in a Tertiary care teaching hospital. A Prospective Observational Study. Imperial Journal of Research 2016;2(6):898.

\section{Abbreviations}

ADR: Adverse Drug Reaction; AOR: Adjusted Odds Ratio, CDC: Center of Disease Control, COR: Crude Odds Ratio, DDI: Drug-Drug Interaction, DRP: Drug Related Problem, JUMC: Jimma University Medical Center, MRP: Medication Related Problem, PDDI: PICU: Pediatric Intensive Care Unit, WHO:world health organization

\section{Declarations}

\section{Acknowledgements}

We would like to thank Jimma university for funding this research. We are also extend our gratitude to all individuals who involved in data collection and also the patients, parents and caregivers who willingly allowed us to use the patient charts and provide us all necessary information.

\section{Authors' contributions}

DFM:- contributed to set the objective, the study design, participated in data analysis, and participated in drafting and editing the manuscript.

DD:- contributed to set the objective, the study design, participated in data analysis, and participated in editing the manuscript.

TM:- contributed to set the objective, the study design, participated in data analysis, and participated in drafting and editing the manuscript. All the authors read and approved th final manuscript.

\section{Declarations}

The authors declare that they have no competing interests.

\section{Authors' Information}

1 Department of Pharmacy, College of Medicine and Health science ,Mizan-Tepi

University,Mizan,Ethiopia_Email: sinaawayya@gmail.com phone $\underline{+251917127556}$ 
2 Department of Clinical Pharmacy, School of Pharmacy, Institute of Health, Jimma University, Jimma, Ethiopia Email: duladessa@gmail.com phone $\underline{+251913858594}$

3 Department of Clinical Pharmacy, School of Pharmacy, Institute of Health, Jimma University, Jimma, Ethiopia_Email: tsegaye.melaku@ju.edu.et phone $+\underline{251913765609}$

\section{Data availability statement:}

The dataset supporting the conclusions of this manuscript is included within the article.

\section{Tables}

Table 1: Baseline socio-demographic characteristics of study participants of JUMC from April 1 to June 30, 2018.

\begin{tabular}{lll}
\hline variables & Frequency(\%)n=304 \\
\hline Sex & Male & $171(56.3)$ \\
& Female & $133(43.7)$ \\
Age & & \\
& Neonate & $42(13.8)$ \\
& Infant & $116(38.2)$ \\
& Toddler & $45(14.8)$ \\
& Preschool & $36(11.8)$ \\
& School age & $38(12.5)$ \\
Adolescent & $27(8.9)$ \\
Weight (kg) & \\
$<5$ & $92(30.3)$ \\
5 to 9.9 & $91(29.9)$ \\
10 to 14.9 & $45(14.8)$ \\
15 to 19.9 & $25(8.2)$ \\
20 to 24.9 & $19(6.3)$ \\
$\geq 25$ & $32(10.5)$ \\
Place of residence & \\
Urban & $110(36.2)$ \\
Rural & $194(63.8)$ \\
\hline
\end{tabular}

Table 2: Clinical characteristics of pediatric patients with infectious disease admitted to pediatric ward of JUMC, from April 1 to June 30, 2018. 


\begin{tabular}{cl}
\hline Variables & Frequency(\% N=304) \\
\hline Comorbidity & $204(67.1)$ \\
Yes & $100(32.9)$ \\
No & \\
Duration of hospital stay & $76(25)$ \\
$\leq 5$ days & $128(42.1)$ \\
$6-10$ days & $100(32.9)$ \\
$\geq 11$ days & \\
Number of infectious disease & $145(47.7)$ \\
1 & $116(38.2)$ \\
2 & $43(14.1)$ \\
Culture done & \\
Yes & $139(45.7)$ \\
No & $165(54.3)$ \\
&
\end{tabular}

Table 3: The common causes of DTPs identified among pediatric patients diagnosed with infectious disease in pediatric ward of JUMC from April 1 to June 30, 2018. 
Non-compliance

Caregiver does not understand the instructions

Drug product is too expensive for the patient

Omission( vein is not visible)

Caregiver forgets to give the medication

Drug product is not available for the patient

Dose too low

Dose is too low to produce the desired response

Dosage interval is too infrequent

Drug interaction

Duration of drug therapy is too short

Ineffective drug therapy

Drug product is not an effective product

Dosage form of the drug product is inappropriate

Condition is refractory to the drug product

Other*

Need additional drug therapy

A medical condition requires the initiation of drug

Preventive drug therapy is required

To attain synergistic effect

\section{Unnecessary}

Multiple drug products are being used

No valid medical indication
102(28.65)

$31(30.4)$

29(28.43)

19(18.63)

12(11.76)

$11(10.78)$

98(27.53)

$54(55.10)$

28(28.57)

$13(13.27$

3(3.06)

41(11.52)

28(68.29)

$6(14.63)$

4(9.76)

3(7.32)

40(11.23)

31(77.5)

$5(12.5)$

4(10)

26(7.3)

17(65.4)

9(34.6)

\section{Dose too high}

39 (10.96)

Dose is too high

Drug interaction

Duration of drug therapy is

long

Dosing frequency is too short

$4(10.25)$

10(2.81)

Adverse drug reaction

drug product causes an allergic reaction $6(60)$

* Microorganism develop resistance to drug product

Table 4: The Class of drugs involved in drug therapy problem among patients with infectious disease at pediatric ward of JUMC from April 1 to June 30, 2018. 


\begin{tabular}{ll}
\hline Class & Frequency(\%N=304) \\
\hline Systemic Anti-infective medicines & $271(76.12)$ \\
Central nervous system medicines & $24(6.74)$ \\
Gastrointestinal medicines & $15(4.21)$ \\
Cardiovascular medicines & $11(3.09)$ \\
Dermatological medicine & $8(2.24)$ \\
Medicines used in endocrine disorder & $6(1.69)$ \\
Respiratory medicines & $5(1.40)$ \\
Others & ${ }^{\circledR}$ \\
\hline
\end{tabular}

() Electrolyte and Acid base balance correcting drugs, Vitamins, Medicines affecting the blood, ophthalmic agents

Table 5: Status of recommendation of intervention provided for pediatric patient with infectious disease in JUMC, 2018.

\begin{tabular}{lr}
\hline Status of recommendation & Frequency (\%) \\
\hline Intervention accepted & $247(69.38)$ \\
Refused & $73(20.51)$ \\
Intervention accepted with modification & $36(10.11)$ \\
\hline Total & $356(100)$ \\
\hline
\end{tabular}

Table 6: Bivariate analysis of factors associated with DTPs among patients with infectious disease admitted to pediatric ward of JUMC from April1 to June 30, 2018 


\begin{tabular}{|c|c|c|c|c|}
\hline \multirow[t]{2}{*}{ Variables } & \multicolumn{2}{|c|}{ DTP } & \multirow[t]{2}{*}{ COR } & \multirow[t]{2}{*}{ P-value } \\
\hline & Yes & No & & \\
\hline \multicolumn{5}{|l|}{ Sex } \\
\hline Male & $129(57.1 \%)$ & $42(53.8 \%)$ & $1.14(0.68-1.91)$ & 0.62 \\
\hline Female & $97(42.9 \%)$ & $36(46.2 \%)$ & 1 & \\
\hline \multicolumn{5}{|l|}{ Age } \\
\hline Neonate & $30(13.3 \%)$ & $12(15.4 \%)$ & 1 & \\
\hline Infant & 88(38.9\%) & $28(35.9 \%)$ & $1.25(0.56-2.77)$ & 0.57 \\
\hline Toddler & $36(15.9 \%)$ & $9(11.5 \%)$ & $1.60(0.59-4.30)$ & 0.35 \\
\hline Preschool & $25(11.1 \%)$ & $11(14.1 \%)$ & $0.90(0.34-2.41)$ & 0.84 \\
\hline School age & $28(12.4 \%)$ & $10(12.8 \%)$ & $1.12(0.41-2.99)$ & 0.82 \\
\hline Adolescent & $19(8.4 \%)$ & $8(10.3 \%)$ & $0.95(0.32-2.75)$ & 0.92 \\
\hline \multicolumn{5}{|l|}{ Duration of hospital stay } \\
\hline$\leq 5$ days & $40(17.7 \%)$ & $36(46.2 \%)$ & 1 & \\
\hline 6 to 10 days & $103(45.6 \%)$ & $25(32.1 \%)$ & $3.70(1.98-6.94)$ & $.0004^{*}$ \\
\hline$\geq 11$ days & 83 (36.7\%) & $17(21.8 \%)$ & $4.39(2.20-8.75)$ & $.0002 *$ \\
\hline \multicolumn{5}{|l|}{ Comorbidity } \\
\hline No & $34(43.6 \%)$ & $44(56.4 \%)$ & 1 & \\
\hline Yes & $170(75.2 \%$ & $56(24.8 \%)$ & $3.92(2.29-6.74)$ & $0.0001 *$ \\
\hline \multicolumn{5}{|l|}{ Polypharmacy } \\
\hline No & $113(50 \%$ & $64(72.1 \%)$ & 1 & \\
\hline Yes & $113(50 \%$ & $14(17.9 \%)$ & $4.57(2.42-8.62)$ & $0.00001^{*}$ \\
\hline \multicolumn{5}{|l|}{ Number of infectious } \\
\hline 1 & $98(43.4 \%)$ & $47(60.3 \%)$ & 1 & \\
\hline 2 & $91(40.5 \%)$ & $25(32.1 \%)$ & $1.74(0.99-3.06)$ & $0.052^{*}$ \\
\hline$\geq 3$ & $37(16.4 \%)$ & $6(7.7 \%)$ & $2.95(1.16-7.49)$ & $0.022^{*}$ \\
\hline \multicolumn{5}{|l|}{ Place of residence } \\
\hline Urban & 79 (35\%) & $31(39.7 \%)$ & 1 & \\
\hline Rural & 147 (65\%) & $47(60.3 \%)$ & $1.22(0.72-2.08)$ & 0.44 \\
\hline \multicolumn{5}{|l|}{ Type of admission } \\
\hline New & 61 (27\%) & $31(39.7 \%)$ & 1 & \\
\hline Transferred & 165 (73\%) & $47(60.3 \%)$ & $1.78(1.03-3.06)$ & $0.036^{*}$ \\
\hline \multicolumn{5}{|l|}{ Culture done } \\
\hline Yes & 105(53.5\% & $34(43.6 \%)$ & 1 & \\
\hline No & $121(50.2 \%)$ & $44(56.4 \%)$ & $0.89(0.53-1.49)$ & 0.66 \\
\hline \multicolumn{5}{|l|}{ Weight (kg) } \\
\hline$<5$ & $70(31 \%)$ & $22(28.2 \%)$ & $0.59(0.15-2.24)$ & 0.44 \\
\hline $5-9.9$ & $69(30.5 \%)$ & $22(28.2 \%)$ & $0.58(0.15-2.20)$ & 0.43 \\
\hline $10-14.9$ & $32(14.2 \%)$ & $13(16.7 \%)$ & $0.46(0.11-1.85)$ & 0.27 \\
\hline $15-19.9$ & $20(8.8 \%)$ & $5(6.4 \%)$ & $0.75(0.15-3.62)$ & 0.72 \\
\hline
\end{tabular}




$\begin{array}{lllll}20-24.9 & 16(7.1 \%) & 3(3.8 \%) & 1 & \\ \geq 25 & 19(8.4 \%) & 13(16.7 \%) & 0.27(.06-1.13) & 0.074^{*}\end{array}$

Number of disease condition

\begin{tabular}{cllll}
1 & $24(10.6 \%)$ & $25(32.1 \%)$ & 1 & \\
2 & $67(29.6 \%)$ & $26(33.3 \%)$ & $2.68(1.30-5.51)$ & $0.007^{*}$ \\
3 & $71(31.4 \%)$ & $17(21.8 \%)$ & $4.35(2.01-9.40)$ & $0.0001^{*}$ \\
$\geq 4$ & $64(28.3 \%)$ & $10(12.8 \%)$ & $6.67(2.79-15.92)$ & $0.0001^{*}$ \\
\hline
\end{tabular}

Table 7: Multivariate logistic regression analysis of predictors of DTPs in pediatric ward of JUMC, 2018.

\begin{tabular}{|c|c|c|c|}
\hline Variables & COR $(95 \% \mathrm{CI})$ & AOR(95\%CI) & P-value \\
\hline \multicolumn{4}{|c|}{ Duration of hospital stay } \\
\hline$\leq 5$ days & 1 & 1 & \\
\hline 6 to 10 days & $3.70(1.98-6.94)$ & $3.37(1.71-6.64)$ & $0.0004 *$ \\
\hline$\geq 11$ days & $4.39(2.20-8.75)$ & 3.86(1.84-8.08) & $0.0003 *$ \\
\hline \multicolumn{4}{|l|}{ Polypharmacy } \\
\hline No & 1 & 1 & \\
\hline Yes & $4.57(2.42-8.62)$ & $3.16(1.61-6.20)$ & $0.001 *$ \\
\hline \multicolumn{4}{|l|}{ Comorbidity } \\
\hline No & 1 & 1 & \\
\hline Yes & $3.92(2.29-6.74)$ & $3.39(1.89-6.08)$ & $0.00004^{*}$ \\
\hline \multicolumn{4}{|c|}{ Number of infectious disease } \\
\hline 1 & 1 & 1 & \\
\hline 2 & $1.74(0.99-3.06)$ & $1.19(0.61-2.32)$ & 0.59 \\
\hline$\geq 3$ & 2.95(1.16-7.49) & $1.18(0.39-3.57)$ & 0.76 \\
\hline \multicolumn{4}{|l|}{ Weight(kg) } \\
\hline$<5$ & $0.59(0.15-2.24)$ & $0.66(0.15-2.84)$ & 0.58 \\
\hline $5-9.9$ & $0.58(0.15-2.20)$ & $0.82(0.19-0.34)$ & 0.79 \\
\hline $10-14.9$ & $0.46(0.11-1.85)$ & $0.60(0.13-2.68)$ & 0.50 \\
\hline $15-19.9$ & $0.75(0.15-3.62)$ & $0.82(0.14-4.61)$ & 0.82 \\
\hline $20-24.9$ & 1 & 1 & \\
\hline$\geq 25$ & $0.27(.06-1.13)$ & $0.33(0.33-1.56)$ & 0.16 \\
\hline \multicolumn{4}{|c|}{ Number of disease condition } \\
\hline 1 & 1 & 1 & \\
\hline 2 & $2.68(1.30-5.51)$ & $0.95(0.30-2.99)$ & 0.93 \\
\hline 3 & $4.35(2.01-9.40)$ & $0.72(0.14-3.54)$ & 0.69 \\
\hline$\geq 4$ & $6.67(2.79-15.92)$ & $0.75(1.12-4.44)$ & 0.75 \\
\hline
\end{tabular}




\section{Figures}

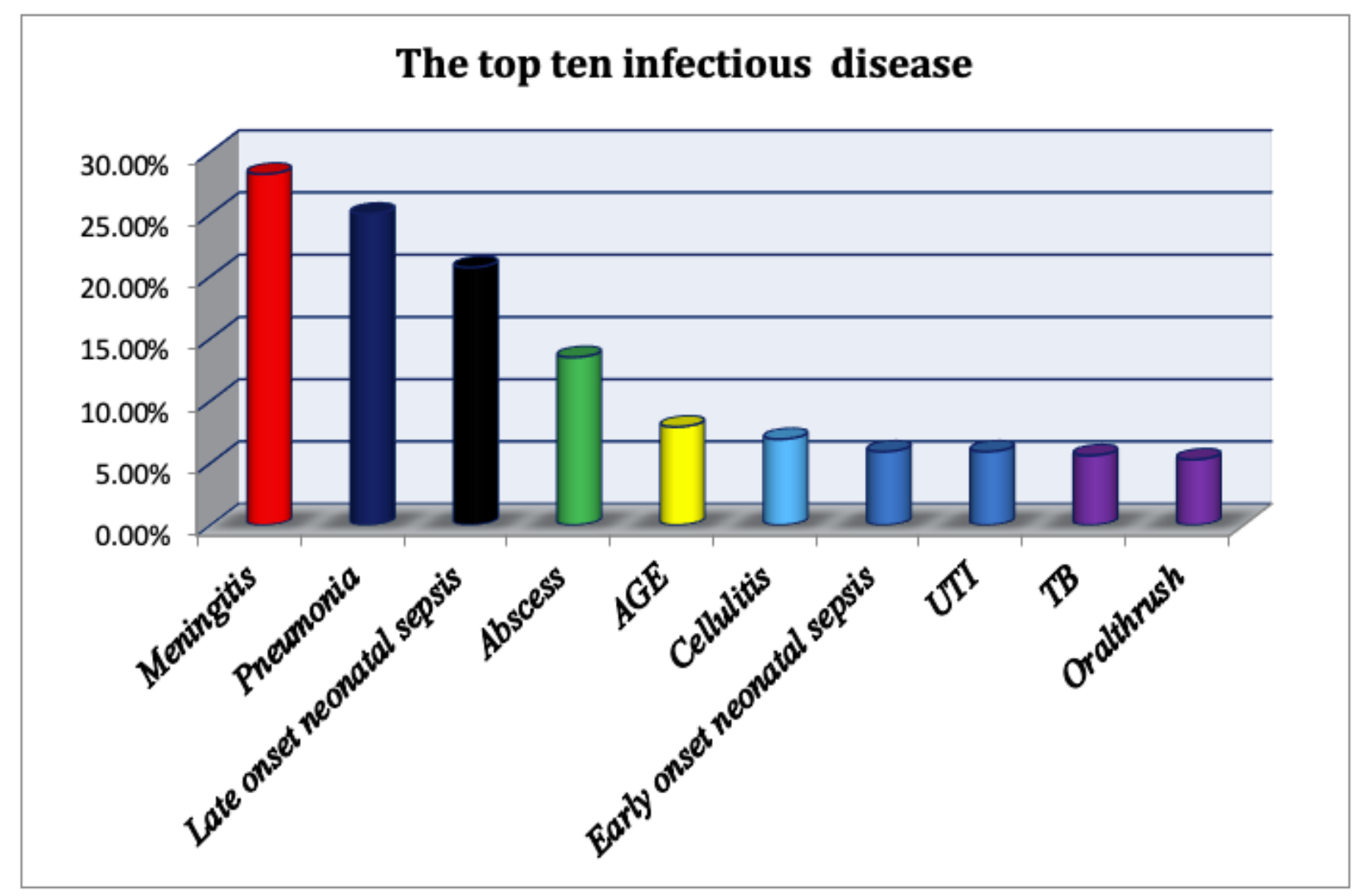

Figure 1

The top ten infectious diseases diagnosed among patients admitted to pediatric ward of JUMC from April 1 to June $30,2018$. 


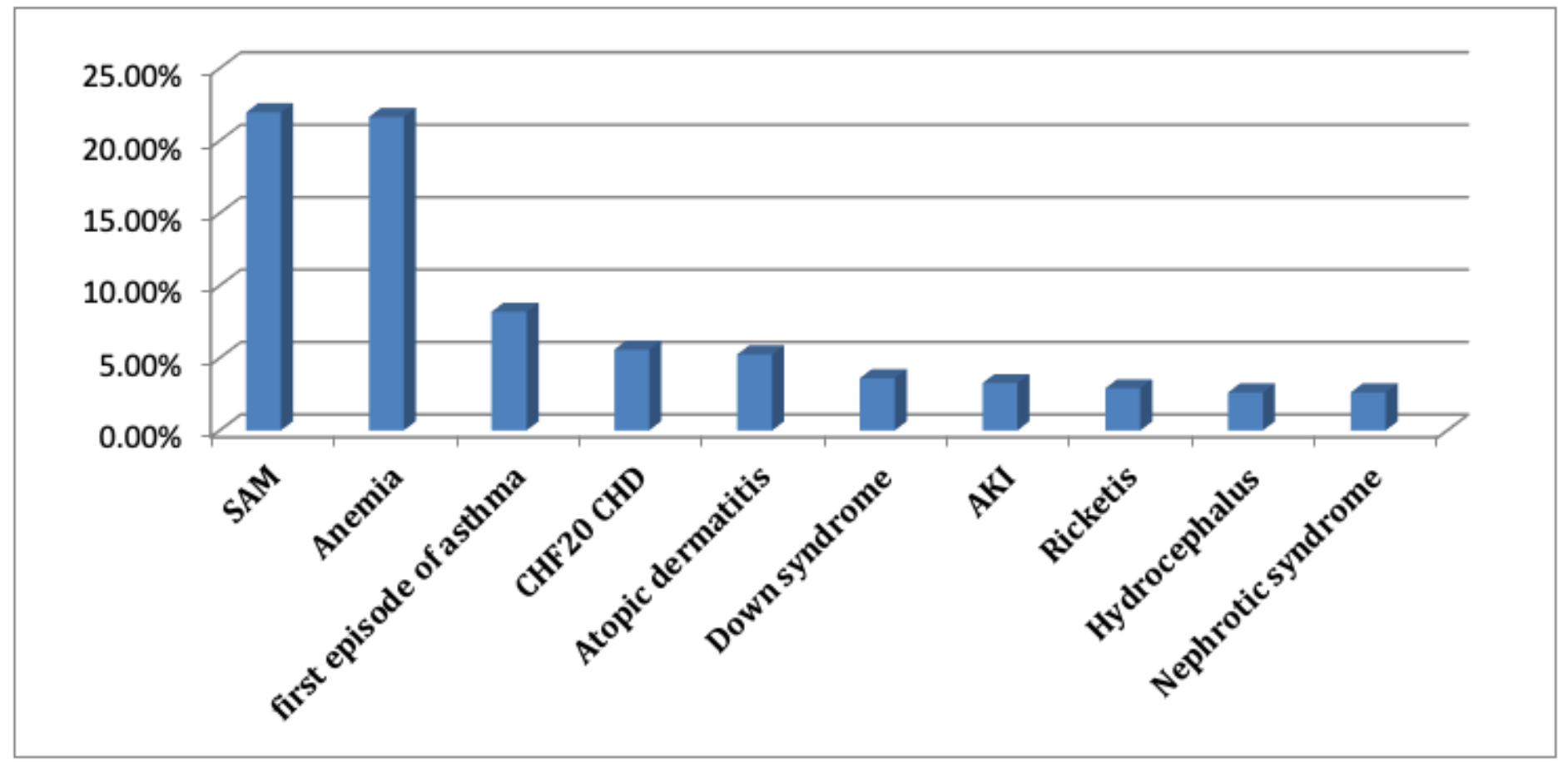

SAM: severe acute malnutrition; AKI: acute kidney injury; CHF20CHD: congestive heart failure secondary to congenital heart disease

Figure 2

The top ten comorbidities diagnosed among patient with infectious disease at pediatrics ward of JUMC from April 1 to June 30, 2018

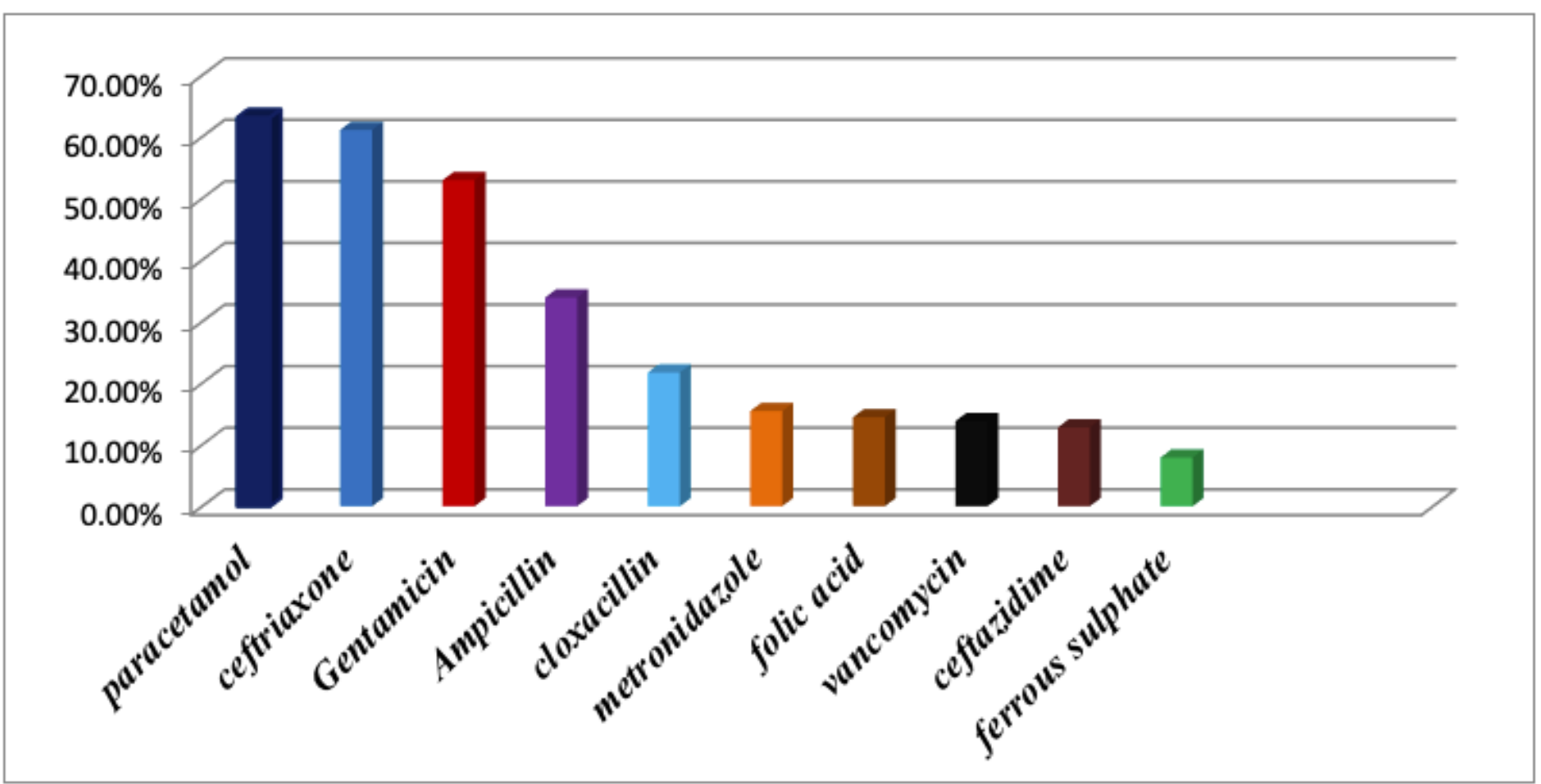




\section{Figure 3}

The top ten prescribed medications in pediatrics patients diagnosed with infectious in pediatrics ward of JUMC from April 1 to June 30, 2018.

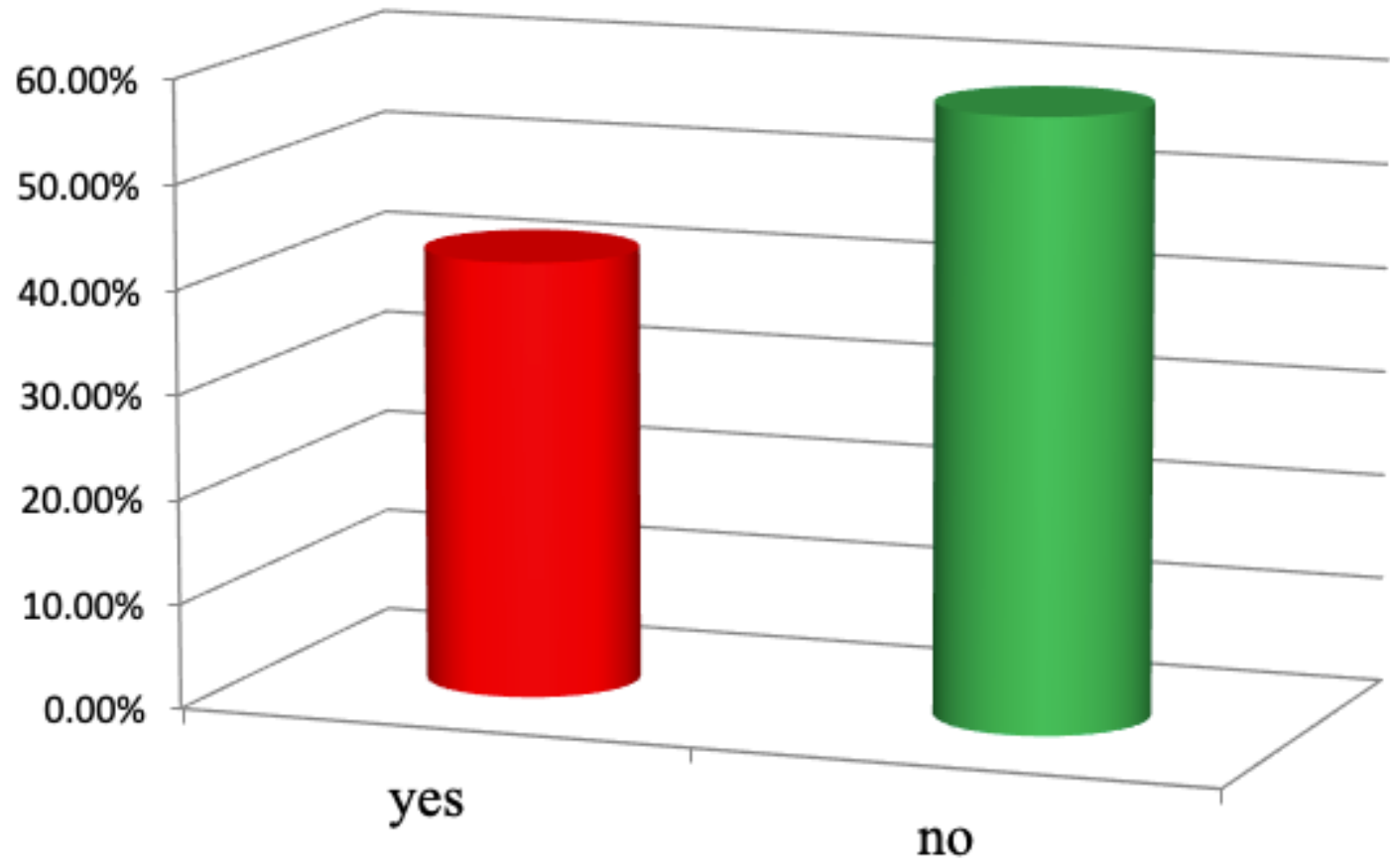

\section{Figure 4}

Polypharmacy among patients with infectious disease in pediatrics ward of JUMC from April 1 to June 30, 2018. 


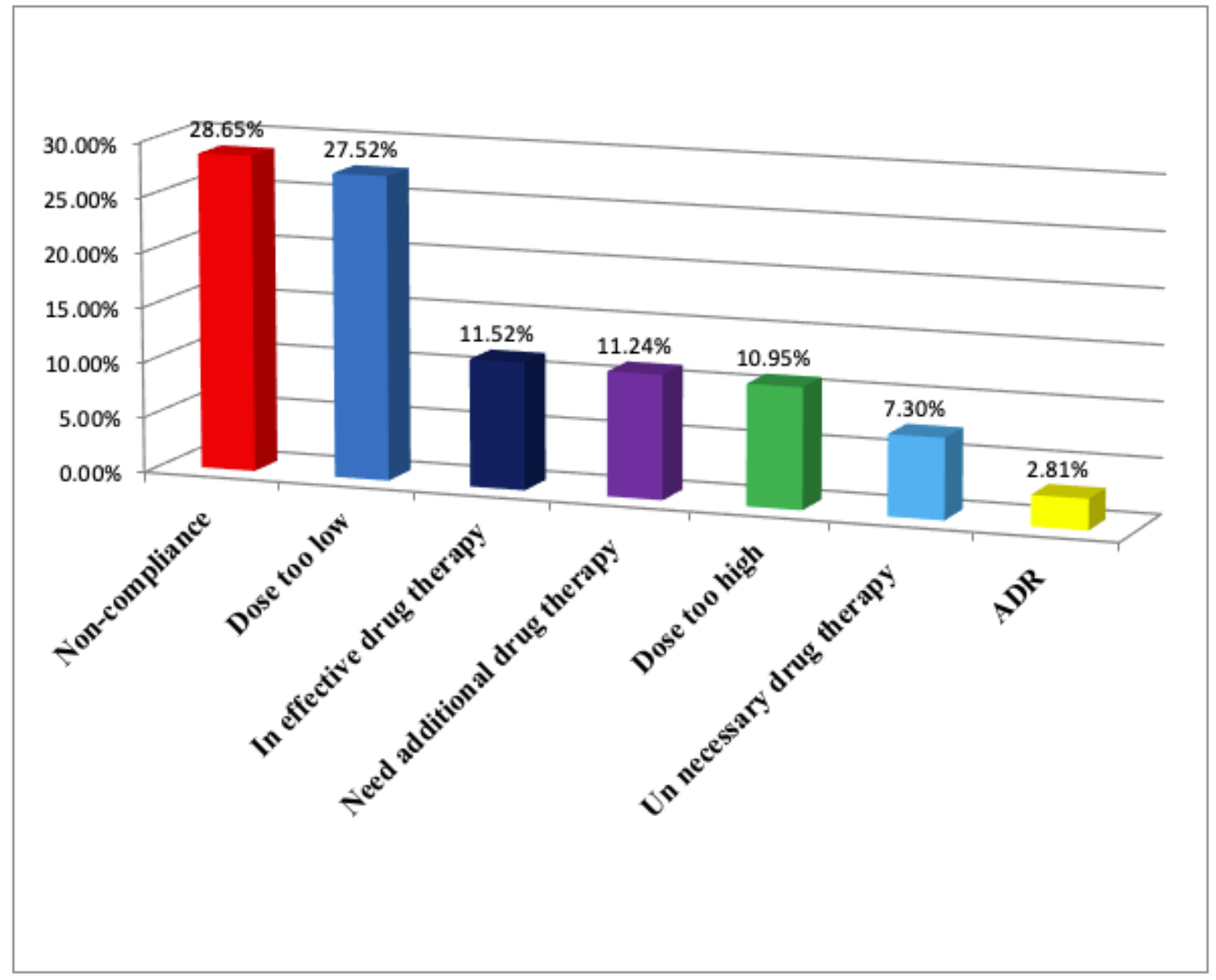

\section{Figure 5}

Types of Drug therapy problems identified among pediatric patients diagnosed with infectious disease at pediatric ward of JUMC from April 1 to June 30, 2018.

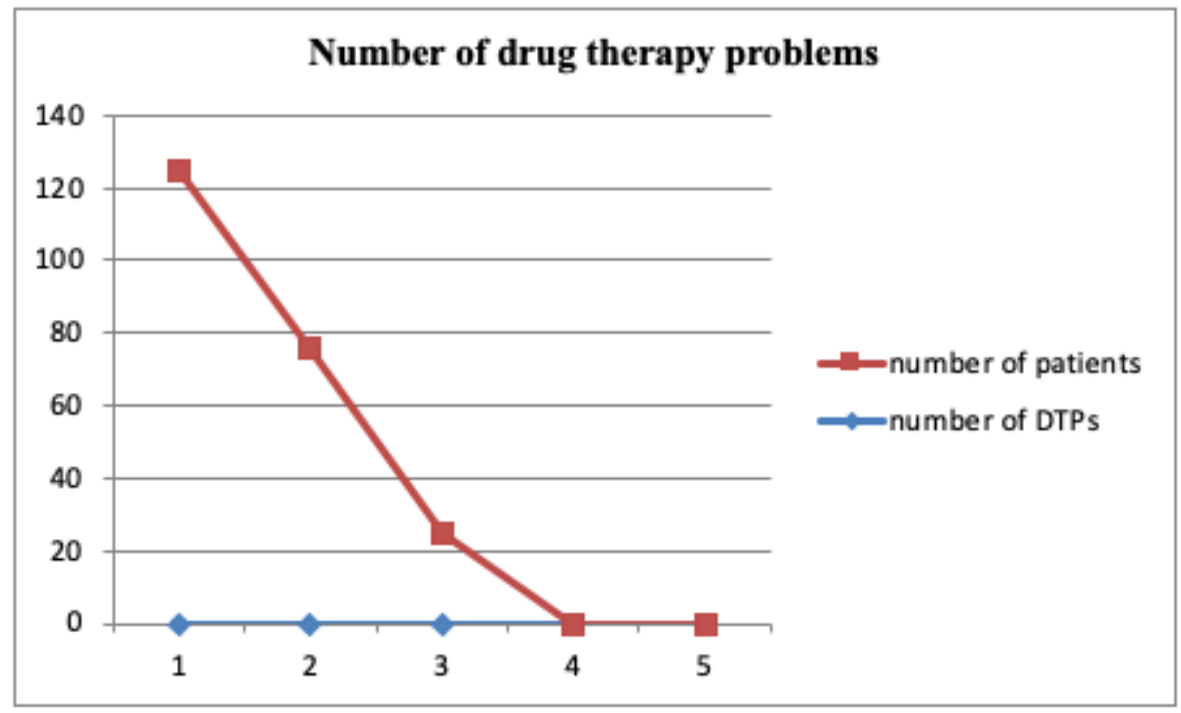

Figure 6 
Number of drug therapy problems per patient who had experienced drug therapy problem at pediatric ward of JUMC from April1 to June 30, 2018

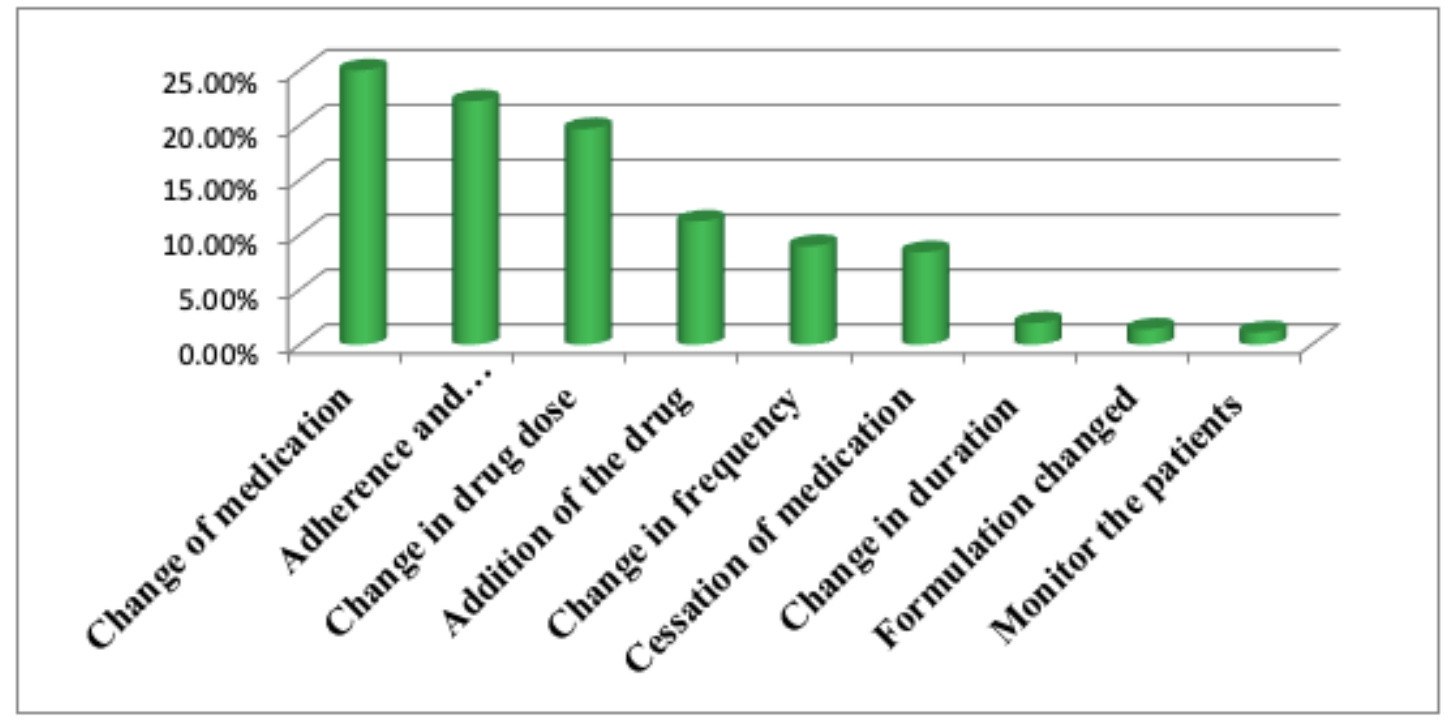

Figure 7

Type of intervention provided for patients diagnosed with infectious disease admitted to pediatric of JUMC from April 1 to June 30, 2018

\section{Supplementary Files}

This is a list of supplementary files associated with this preprint. Click to download.

- Equation2.png

- Equation1.png 